\title{
HUBUNGAN INDEKS MASSA TUBUH (IMT) DENGAN DERAJATDISMENORE PADA MAHASISWI KEDOKTERAN FAKULTAS KEDOKTERAN DAN ILMU KESEHATAN UNIVERSITAS JAMBI
}

\author{
Asro Harahap ${ }^{1}$, Jelica Oktaviani², Erny Kusdiyah ${ }^{3}$, Esa Indah Ayudia Tan ${ }^{4}$, Amelia Dwi $^{2}$ \\ $\mathbf{F}^{5}$, Herlambang ${ }^{6}$ \\ ${ }^{1}$ Kantor kesehatan pelabuhan kelas III Dumai \\ ${ }^{2}$ Mahasiswa Program Studi Kedokteran, Fakultas Kedokteran dan IImu Kesehatan Universitas Jambi \\ ${ }^{3,4,5,6}$ Dosen Program Studi Kedokteran, Fakultas Kodokteran dan Ilmu Kesehatan Universitas Jambi \\ Email: asrohayani.16@gmail.com
}

\begin{abstract}
Background : Dismenorrhea is the most common gynecological complaint experienced by adolescents and women who are in their early adulthood. Dismenorrhea can affect a woman's quality of life during reproductive times, such as loss of employment opportunities, disrupting learning activities in school and disrupting family life. One of the causes often associated with dismenorrhea is the Body Mass Index (BMI). Abnormal BMI can cause pain in menstruation or dismenorrhea. Objective : Knowing the relationship of Body Mass Index (BMI) with the degree of dismenorrhea in medical students FKIK University of Jambi.

Method : This research uses cross sectional design. The population in this study was medical student of FKIK University of Jambi class of 2018 and 2019. The number of samples in this study was 104 and taken random sampling, by distributing questionnaires in the form of google form to respondents.

Result : The results showed that there is a relationship of Body Mass Index (BMI) with the degree of dismenorrhea obtained p-value $=0.000$. Obtained underweight BMI data and suffered a mild dismenorrhea - while as many as 19 people (24.67\%), who experienced severe dismenorrhea as many as 2 people (7.41\%). For overweight BMI and mild dismenorrhea - moderate as many as 9 people (11.69\%), who experienced severe dismenorrhea as many as 17 people (62.96\%). For normal BMI and mild dismenorrhea - moderate as many as 49 people (63.64\%), who experienced severe dismenorrhea as many as 8 people (29.63\%).
\end{abstract}

Conclusion: There is a relationship between Body Mass Index (BMI) and degree of dismenorrhea.

Keywords: Body Mass Index, Dismenorhea

\section{ABSTRAK}

Latar Belakang : Dismenore merupakan keluhan ginekologis yang paling sering dialami oleh remaja dan perempuan yang menginjak usia dewasa muda. Dismenore dapat mempengaruhi kualitas hidup perempuan selama masa reproduktif, seperti kehilangan kesempatan kerja, mengganggu kegiatan belajar di sekolah dan mengganggu kehidupan keluarga. Salah satu penyebab yang sering dihubungkan dengan dismenore adalah Indeks Massa Tubuh (IMT). IMT yang tidak normal dapat menyebabkan nyeri pada menstruasi atau dismenore. Tujuan Penelitian : Mengetahui hubungan Indeks Massa Tubuh (IMT) dengan derajat dismenore pada mahasiswi kedokteran FKIK Universitas Jambi.

Metode : Penelitian ini menggunakan rancangan cross sectional. Populasi dalam penelitian ini adalah mahasiswi kedokteran FKIK Universitas Jambi angkatan 2018 dan 2019. Jumlah sampel dalam penelitian ini adalah 104 dan dimbil secara random sampling, dengan membagikan kuesioner berupa google form pada responden.

Hasil : Hasil penelitian menunjukkan ada hubungan Indeks Massa Tubuh (IMT) dengan derajat dismenore diperoleh nilai $\mathrm{p}$-value $=0,000$. Didapatkan data IMT underweight dan mengalami dismenore ringan - sedang sebanyak 19 orang (24,67\%), yang mengalami dismenore berat sebanyak 2 orang (7,41\%). Untuk IMT overweight 
dan mengalami dismenore ringan - sedang sebanyak 9 orang $(11,69 \%)$, yang mengalami dismenore berat sebanyak 17 orang (62,96\%). Untuk IMT normal dan mengalami dismenore ringan - sedang sebanyak 49 orang $(63,64 \%)$, yang mengalami dismenore berat sebanyak 8 orang $(29,63 \%)$.

Kesimpulan : Terdapat hubungan antara Indeks Massa Tubuh (IMT) dengan derajat dismenore.

\section{Kata Kunci : Indeks Massa Tubuh, Derajat Dismenore}

\section{PENDAHULUAN}

Menstruasi atau yang dikenal juga dengan haid merupakan suatu proses fisiologis wanita yang terjadi secara berkala dan dipengaruhi oleh hormon reproduksi. Pada saat menstruasi terjadi perdarahan periodik akibat terlepasnya mukosa rahim karena sel telur tidak dibuahi oleh sperma. ${ }^{1}$ Pada saat menjelang menstruasi atau selama fase menstruasi sering dijumpai gangguan berupa nyeri menstruasi atau disebut juga dismenore. Dismenore merupakan nyeri siklis pada panggul atau perut bagian bawah. Dismenore dibedakan menjadi dismenore primer dan dismenore sekunder. Dismenore primer merupakan nyeri menstruasi yang dijumpai tanpa kelainan pada alat-alat genital yang nyata, sedangkan dismenore sekunder disebabkan oleh kelainan ginekologik atau didapat seperti endometriosis, adenomiosis uteri, salpingitis kronika, dan lainlain. $^{2}$ Dampak dari dismenore berupa gangguan dalam beraktivitas dan menurunkan kualitas hidup seseorang. Dismenore juga dapat menyebabkan infertilitas dan gangguan fungsi seksual jika tidak ditangani, depresi, serta alterasi aktivitas autonomik kardiak. ${ }^{3}$ Menurut data World Health Organization (WHO), didapatkan kejadian dismenore pada wanita sebanyak 1.769.425 jiwa (90\%) dengan 10-15\% mengalami dismenore berat. ${ }^{4}$ Begitu pula angka kejadian dismenore di Indonesia cukup tinggi yaitu sebesar $54,89 \%$ dismenore primer dan 9,36\% dismenore sekunder. ${ }^{5}$ Adapun angka kejadian dismenore di Jawa Barat tahun 2015 yaitu sebesar $72,89 \%$ dismenore primer dan $27,11 \%$ dismenore sekunder. ${ }^{6}$

Indeks Massa Tubuh (IMT) merupakan alat atau cara sederhana untuk memantau status gizi seseorang. Indeks Massa Tubuh (IMT) digunakan untuk mengukur lemak tubuh berdasarkan tinggi dan berat badan seseorang. Indeks massa tubuh (IMT) ditentukan dalam skala kilogram dibagi dengan tinggi badan dikuadratkan dalam skala meter. Indeks Massa Tubuh (IMT) dapat diklasifikasikan menjadi underweight, normal, overweight, obesitas 1, dan obesitas 2. Individu dengan Indeks Massa Tubuh (IMT) kurang dari normal menunjukkan rendahnya asupan kalori, berat badan, dan lemak tubuh yang mengganggu sekresi pulsatil gonadotropin pituitari untuk menghasilkan hormon reproduksi sehingga menyebabkan peningkatan kejadian dismenore. Individu dengan Indeks Massa Tubuh (IMT) lebih dari normal menunjukkan peningkatan kadar prostaglandin yang berlebih, sehingga memicu terjadinya spasme miometrium karena prostaglandin yang terdapat dalam darah mirip lemak alamiah yang dapat ditemukan di dalam otot uterus. Indeks Massa Tubuh (IMT) lebih dari normal juga dapat menunjukkan hormon estrogen yang berlebihan karena konversi dari androgen. Beberapa penelitian menunjukkan hubungan antara Indeks Massa Tubuh (IMT) dengan dismenore. ${ }^{7}$ Pada penelitian Retno 
Ekowati di Bandung menunjukkan bahwa 87 dari 121 responden dalam penelitiannya adalah dalam keadaan kelebihan berat badan dan menderita dismenore. ${ }^{8}$ Melihat dari dampak yang diakibatkan oleh dismenore dan adanya penelitian yang mengatakan bahwa Indeks Massa Tubuh (IMT) menjadi salah satu faktor dari dismenore, serta belum adanya penelitian mengenai hubungan Indeks Massa Tubuh (IMT) dengan dismenore di Jambi, maka penulis tertarik untuk mengadakan penelitian mengenai hubungan Indeks Massa Tubuh (IMT) dengan derajat dismenore pada mahasiswi kedokteran Universitas Jambi.

\section{METODE}

Desain penelitian ini menggunakan survey analitik dengan pendekatan Cross Sectional. Penelitian ini bertujuan untuk mengetahui hubungan Indeks Massa Tubuh (IMT) dengan derajat dismenore pada mahasiswi kedokteran Universitas Jambi. Teknik pengumpulan data dalam penelitian ini yaitu peneliti membagikan lembar informed consent, biodata diri, dan membagikan lembar kuesioner dismenore dengan menggunakan google form. Jenis data yang diambil adalah data primer, kemudian data dianalisa univariat dan bivariat menggunakan perangkat lunak komputer dengan program Statistical Product and Service Solution (SPPS) 25.0 for windows dan dianalisa dengan teknik perhitungan statistik Chi Square. Penelitian ini dilaksanakan pada bulan Mei - September 2020 dan populasi pada penelitian ini adalah mahasiswi Universitas Jambi angkatan 2018 dan 2019 dengan sampel berjumlah 104 orang.

\section{HASIL DAN PEMBAHASAN}

Hubungan antara indeks massa tubuh dan derajat dismenore pada mahasiswi fakultas kedokteran Universitas Jambi angkatan 2018 dan 2019, hasil tabulasi silang antara variabel indeks massa tubuh dengan derajat dismenore dapat dilihat pada tabel.

Tabel 1. Hubungan Indeks Massa Tubuh dengan Derajat Dismenore

\begin{tabular}{|c|c|c|c|c|c|c|c|}
\hline \multirow{3}{*}{$\begin{array}{c}\text { Indeks Massa } \\
\text { Tubuh }\end{array}$} & \multicolumn{4}{|c|}{ Derajat Dismenore } & \multicolumn{2}{|c|}{ Total } & \multirow[t]{2}{*}{$\mathrm{P}$} \\
\hline & \multicolumn{2}{|c|}{ Derajat Ringan - Sedang } & \multicolumn{2}{|c|}{ Derajat Berat } & & & \\
\hline & $\mathrm{n}$ & $\%$ & $\mathrm{n}$ & $\%$ & $n$ & $\%$ & Value \\
\hline Underweight & 19 & $24,67 \%$ & 2 & $7,41 \%$ & 21 & $20,19 \%$ & 0,000 \\
\hline Normal & 49 & $63,64 \%$ & 8 & $29,63 \%$ & 57 & $54,81 \%$ & \\
\hline $\begin{array}{l}\text { Overweight } \\
\text { obesitas }\end{array}$ & 9 & $11,69 \%$ & 17 & $62,96 \%$ & 26 & $25 \%$ & \\
\hline Jumlah & 77 & $74,04 \%$ & 27 & $25,96 \%$ & 104 & $100 \%$ & \\
\hline
\end{tabular}

Dari hasil analisis bivariat antara IMT dengan derajat dismenore dapat dilihat bahwa responden yang IMT nya underweight $(<18,5)$ dan mengalami dismenore ringan - sedang sebanyak 19 orang $(24,67 \%)$, yang mengalami dismenore berat sebanyak 2 orang (7,41\%). Untuk responden yang memiliki IMT overweight ( $\geq 23)$ dan mengalami dismenore ringan - sedang sebanyak 9 orang $(11,69 \%)$, yang mengalami dismenore berat sebanyak 17 orang $(62,96 \%)$. Sedangkan untuk responden yang IMT nya normal $(18,5-22,9)$ dan mengalami dismenore ringan - sedang sebanyak 49 orang $(63,64 \%)$, yang mengalami dismenore berat sebanyak 8 orang $(29,63 \%)$. 
Hasil analisis uji kai kuadrat menunjukkan bahwa nilai $p=0,000$ ( $p$ kurang dari 0,05) sehingga dapat disimpulkan bahwa ada hubungan bermakna antara Indeks Massa Tubuh dengan derajat dismenore pada mahasiswi fakultas kedokteran Universitas Jambi angkatan 2018 dan 2019. Sejalan dengan penelitian Harmoni, diperoleh hasil terdapat hubungan antara IMT dengan derajat dismenore dengan $p=0,000$ dan juga penelitian yang dilakukan Gurdip Kaur dari Departemen of Obstetrics \& Gynaecology, Govt. Medical College/ Rajindra Hospital, India menyatakan terdapat hubungan antara Indeks Massa Tubuh dengan derajat dismenore. ${ }^{27,28}$ Penelitian ini sebelumnya juga sudah dilakukan oleh Budiman Hartono dan Fallentino Christman Leuhery pada responden FK UKRIDA dan hasilnya sesuai dengan penelitian ini, yang menunjukkan bahwa responden mayoritas IMT normal dan mengalami nyeri dismenore derajat ringan - sedang. ${ }^{29}$ Penelitian ini juga sejalan dengan penelitian yang dilakukan oleh Karim yang di laksanakan di Jakarta Barat terdapat 49,9\% mengalami dismenore ringan. ${ }^{30}$

Pada penelitian ini didapatkan adanya hubungan antara Indeks Massa Tubuh yang tidak normal (underweight dan overweight obesitas) dengan derajat dismenore. Hal ini sesuai dengan teori yang menjelaskan bahwa salah satu permasalahan yang dapat menimbulkan dismenore adalah status gizi. Overweight atau obesitas merupakan salah satu faktor resiko dari dismenore. Namun di sisi lain, seseorang dengan underweight ternyata juga dapat mengalami dismenore. Mekanisme yang mendasari hubungan antara IMT dengan dismenore belum dipahami secara keseluruhan, dan kemungkinan terdapat perbedaan antara mekanisme pada wanita underweight dan overweight - obesitas. ${ }^{31}$ Asupan makanan yang kurang pada wanita dengan status gizi underweight dapat memicu dismenore, karena status gizi merupakan salah satu hal yang penting dan dapat mempengaruhi pertumbuhan dan fungsi organ tubuh sehingga dapat menyebabkan terganggunya fungsi reproduksi termasuk haid. Rendahnya asupan kalori, berat badan, dan lemak tubuh mengganggu sekresi pulsatil gonadotropin pituitari yang menyebabkan peningkatan kejadian dismenore. ${ }^{32}$ Namun, jumlah tertentu dari lemak tubuh dapat menjadi pengaruh yang penting untuk memelihara siklus ovulasi yang normal dimana terlalu banyak atau terlalu sedikit lemak dapat mempengaruhi terganggunya kesehatan reproduksi. ${ }^{31}$

Nyeri dismenore dapat terjadi karena ada peningkatan produksi prostaglandin. Peningkatan ini akan mengakibatkan kontraksi uterus dan vasokonstriksi pembuluh darah, maka aliran darah yang menuju ke uterus menurun sehingga uterus tidak mendapat suplai oksigen yang adekuat sehingga menyebabkan nyeri. Intensitas nyeri setiap individu berbeda dipengaruhi oleh deskripsi individu tentang nyeri, persepsi dan pengalaman nyeri. Nyeri yang dirasakan terjadi karena adanya peningkatan produksi prostaglandin yang berlebihan, yang merangsang hiperaktivitas uterus, sedangkan perbedaan intensitas nyeri yang dialami tersebut tergantung pada kadar prostaglandin yang diproduksi. Beberapa penelitian membuktikan bahwa wanita yang mengalami dismenore akan mengalami peningkatan kadar prostaglandin terutama pada dua hari pertama menstruasi. Kadar prostaglandin tersebut mencapai 5 - 13 kali lebih tinggi disbandingkan 
pada wanita yang tidak mengalami dismenore. Meskipun stimulus nyeri disebabkan oleh hal yang sama yaitu kontraksi uterus namun reaksi yang ditimbulkan oleh tiap individu berbeda dan intensitas nyeri yang dirasakan pun berbeda. ${ }^{33}$

Semakin tinggi kadar kolesterol juga akan mempengaruhi tinggi derajat dismenore yang dialami seseorang karena adanya dominasi estrogen pada fase luteal dan kekurangan produksi progesteron. Dampak dari kolesterol yang meningkat adalah terjadi peningkatan stimulant estrogen pada endometrium dan mendesak jaringan endometrium untuk proliferasi dan produksi prostaglandin, sehingga terjadi hiperkontraksi uterus. $^{34}$

\section{Kesimpulan}

Berdasarkan hasil penelitian yang telah dilakukan maka diambil kesimpulan bahwa :

1. Dari 104 jumlah responden, terdapat 21 mahasiswi $(20,19 \%)$ mengalami underweight, 57 mahasiswi $(54,81 \%)$ normal, dan 26 mahasiswi (25\%) mengalami overweight - obesitas disertai dismenore.

2. Didapatkan 19 mahasiswi (24,67\%) mengalami underweight, 49 mahasiswi (63,64\%) normal, dan 9 mahasiswi $(11,69 \%)$ mengalami overweight disertai dismenore derajat.ringan sedang. Pada dismenore derajat berat didapatkan 2 mahasiswa (7,41\%) mengalami underweight, 8 mahasiswi $(29,63 \%)$ normal, dan 17 mahasiswi $(62,96 \%)$ mengalami overweight obesitas.

3. Terdapat hubungan bermakna antara Indeks Massa Tubuh (IMT) dengan derajat dismenore pada mahasiswi fakultas kedokteran Universitas Jambi $(p=0,000)$.

\section{REFERENSI}

1. Universitas Nasional. Manajemen Kesehatan Menstruasi. Universitas Nasional. 2017:181.

2. Puspitasari, I., Rumini, \& Mukarromah, S. Pengaruh Latihan Senam dan Daya Tahan Tubuh terhadap Respon Nyeri Haid ( Dysmenorrhea ). Journal of Physical Education and Sport. 2017;6(2):165-171.

3. Hailemeskel, S.,Demissie, D., \& Assefa, N. Primary dysmenorrhea

4. magnitude, associated risk factors, and its effect on academic performance: evidence from female uniersity students in ethiopia. International Journal Womens Health.Dovepress. 2016;8:489-496.

5. Savitri, R. Gambaran Skala Nyeri Haid pada Usia Remaja. Artikel Penelitian. Jurnal Unsika. 2015.

6. Dahlan, A. Pengaruh Terapi Kompres Hangat Terhadap Nyeri Haid (Dismenorea) Pada Siswi Smk Perbankan Simpang Haru Padang. Journal Endurance. 2017 Feb;2(1).

7. Andriyani. Hubungan Antara Usia Menarche Dan Lama Menstruasi Dengan Kejadian Dismenore Primer Pada Remaja Putri. Jurnal UMS. 2016.

8. Dhara S, Chatterjee K. A study of VO2 max in relation with body mass index (BMI) of physical education students. Res. J. Phys. Educ. Sci. 2015 Jun 9-12;3(6):2320-9011.

9. Tresnasari C. Hubungan Antara Indeks Massa Tubuh dengan Kejadian Dismenore Primer pada Mahasiswi Keodkteran Unisba Tingkat 1 Tahun 2016 Periode Maret - April. Bandung. 2016;2(2).

10. Thiyagarajan DK, Basit H, Jeanmonod R. Physiology, Menstrual Cycle. 2019 Apr 24. Treasure Island (FL): StatPearls Publishing; 2020 Jan. Available from: https://www.ncbi.nlm.nih.gov/books/NBK500020 
11. Simanjuntak P. Gangguan Haid dan Siklusnya. Dalam: Prawirohardjo, Sawrwono, Wiknjosastro, Hanifa. 3rd ed. Jakarta: Bina Pustaka Sarwono Prawirohardjo; 2014:229-232.

12. Arini, D., Saputri, D. I., Supriyanti, D., \& Ernawati, D. Pengaruh Senam Yoga Terhadap Penurunan Intensitas Nyeri Haid Pada Remaja Mahasiswi Keperawatan Stikes Hang Tuah Surabaya. Jurnal Keperawatan, 2020;2(1): 46-54.

13. Nurwana, Sabilu Y, Fachlevy AF. Analisis faktor yang berhubungan dengan kejadian dismenorea pada remaja putri di SMA Negeri 8 Kendari tahun 2016. Kendari,2017;2(6):1-14.

14. Lasmi KKH, Wibawa A, Mullarta IM. Hubungan antara indeks massa tubuh (IMT) kategori underweight dengan tingkat nyeri dysmenorrhea primer remaja putri sekolah menengah pertama. Jakarta: Majalah IImiah Fisioterapi Indonesia.2017;6(3):27.

15. Prakasiwi, I. Pengaruh peregangan (Stretching) terhadap penurunan nyeri disminorea. Universitas Aisyiyah Yogyakarta. 2017.

16. Saraswati, S. 52 Penyakit Perempuan. Yogyakarta : Ar-Ruzz MediaGroup. 2010.

17. Nadia, I. Hubungan Gaya Hidup dengan Dismenore Primer pada Mahasiswa Fakultas Kedokteran Universitas Lampung. 2017.

18. Santoso. Angka kejadian nyeri haid pada remaja di Indonesia. 2008.

19. lacovides, S., Avidon, I. Baker FC: What we know about primary dysmenorrhea today: a critical review. Hum Reprod Update. 2015; 21(6): 762-78.

20. Manuaba, I. IImu kebidanan Penyakit Kandungan dan KB. Jakarta: EGC. 2015.

21. Resmiati, dkk. Kajian IImiah Problema Kesehatan : Aktivitas Fisik, Magnesium, Status Gizi, dan Riwayat Alergi sebagai Faktor Determinan Dismenore . Jurnal Endurance. 2020 Feb;5(1):79-90.

22. Bavil, Dina Abadi., Dolatian, Mahrokh., Mahmoodi, Zohreh., Baghban, Alireza Akbarzadeh. Comparison of lifestyles of young women with and without primary dysmenorrhea. Electronic Journal Physician. 2016;8(3):2107-14.

23. Ade, Umi Salam. Faktor - Faktor Yang Berhubungan Dengan Kejadian Dismenore Primer Di Pondok Pesantren Al-Imdad Yogyakarta. Yogyakarta. 2019.

24. Judha, Mohamad. Teori pengukuran Nyeri dan Nyeri Persalinan, Nuha Medika, Yogyakarta. 2012.

25. Hoffman. Endometriosis. In: Williams Gynecology. 3rd ed. New York: Mc Graw Hill Education. 2016:23048.

26. National Heart, Lung, and Blood Institute. Calculate your body mass index. National Institutes of Health. Diunduh dari: https://www.nhlbi.nih.gov/health/educational/lose wt/BMl/bmicalc.html.

27. Kementerian Kesehatan Republik Indonesia. Epidemi obesitas. Jakarta: Badan Penelitian dan Perkembangan Kesehatan Kemenkes RI. 2015.

28. Harmoni pratiwi hesti. Hubungan Antara IMT dan Aaktivitas Fisik Dengan Kejadian Dismenore di SMA Batik 1 Surakarta. Jurnal. 2018:1-18.

29. Chauhan M, Kala J. Relation between dysmenorrhea and body mass index in adolescents with rural versus urban variation. J Obstet Gynecol India. 2012;62(4):442-445.

30. Hartono, B dan Leuhery, FC. Hubungan Indeks Massa Tubuh terhadap Dysmenorrhea pada Mahasiswi Fakultas Kedokteran Universitas Kristen Krida Wacana Angkatan 2015. Jkdoktmeditek. 2020;26(1):1722.

https://ejournal.ukrida.ac.id/ojs/index.php/Meditek/article/view/1797.DOl:https://doi.org/10.36452/jkdokt meditek.v26i1.1797.

31. Karim A. Kejadian Dismenore Berdasarkan Karakteristik Orang Dan Waktu Serta Dampaknya.2016. 
32. Beddu, S., Mukarramah, S. \& Lestahulu, V. Hubungan Status Gizi dan Usia Menarche dengan Dismenore Primer pada Remaja Putri. The Southeast Asian Journal of Midwifery. 2015;1(1):16-21.

33. Mohapatra, D. et al. A Study of Relation between Body Mass Index and Dysmenorrhea and its Impact on Daily Activitied of Medical Students. Asian Journal of Pharmceutical and Clinical Research. 2016;9:297299.

34. Bakay, H. Ulubaşoğlu1, T. Atan, H. Alaçam, D. Güven, S. Batioğlu. The Effect Of Physical Activity On The Levels Of The Hormones, Serotonin And Melatonin In Premenstrual Syndrome. Clin. Exp. Obstet. Gynecol. 2018:425-7.

35. Ashfaq R, Shaista Jabeen. Association Between The Prevalence of Premenstrual Syndrome and Weight Status of Adolescent Girls (11- 21 years). MedCrave. Advances in Obesity, Weight Management \& Control. 2017;6(1). 